\title{
Functional Nanostructures for Sensitive, Selective, and Reliable Gas Sensors
}

\author{
Jong-Heun Lee ${ }^{1}$ \\ ${ }^{1}$ Department of Materials Science and Engineering, Korea University, Seoul 136-713, \\ Republic of Korea \\ jongheun@korea.ac.kr
}

\begin{abstract}
Oxide semiconductor gas sensors with high response, rapid responding/recovering speed, selectivity, and low humidity dependence are designed by controlling the sizes, dimensions, morphologies, assembled configurations, nano-porosities, $\mathrm{p}-\mathrm{n}$ junctions and surface modification of oxide nanostructures. The contribution consists of hierarchical and hollow nanostructures for highly sensitive and rapid responding sensors, the enhancement of gas response and selectivity by surface modification of oxide nanostructures, gas sensors using nano-scale oxide $p-n$ junctions, and the strategy to decrease humidity dependence of gas sensing characteristics.
\end{abstract}

Key words: hierarchical nanostructures, hollow nanostructures, surface modification, p-n junctions, humidity dependence

\section{Hierarchical and hollow nanostructures}

The gas response, responding speed, and stability of chemoresistive oxide semiconductor gas sensors are closely dependent upon the sizes, dimensions, morphologies, and porosities of nanostructures. Hierarchical and hollow nanostructures are the higher dimensional structures that are assembled from low dimensional, nano-building blocks such as $0-D$ nanoparticles, 1-D nanowires/nanorods, and 2D nanosheets (Fig. 1). Hierarchical nanostructures are advantageous to design the high-performance gas sensors on account of their well-aligned nano-porous structures without sacrificing the high surface area to volume ratio [1]. Hollow structures with thin and permeable shell layers are also very attractive nanoarchitectures for gas sensors [1].

Gas sensing reaction of n-type oxide semiconductors consists of the in-diffusion of analyte gas to the sensor surface and the oxidation of analyte gas with the reaction of negatively charged surface oxygen. The full electron depletion can be achieved when the particle sizes are smaller than 2 times of electron depletion layer, which is very advantageous to accomplish high gas responses. However, as the particle size decreases, the nanoparticles tend to form large and dense secondary aggregates due to strong van der Waals attraction. When the in-diffusion of analyte gases into the inner parts of secondary aggregates becomes difficult, the gas response can be significantly decreased (Fig. 2a). In addition, the sluggish in-diffusion can affect the gas responding speed if the rate of sensing reaction is determined by the gas diffusion.

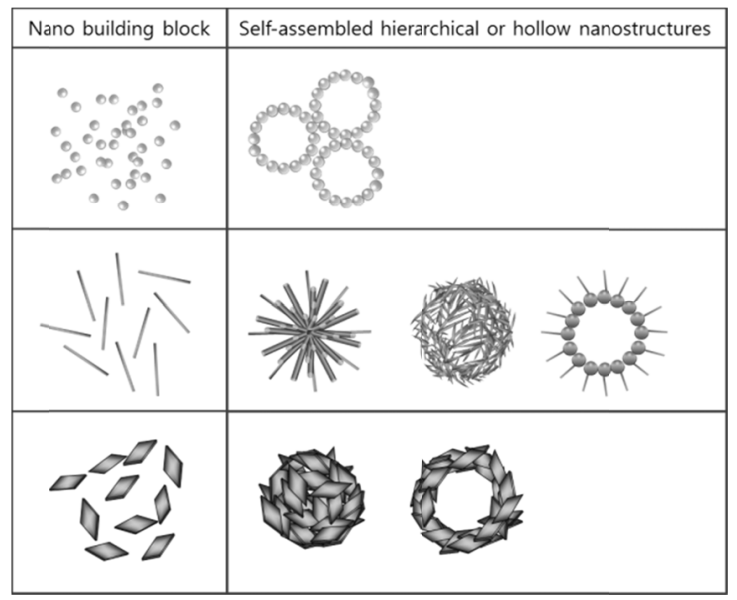

Fig. 1 Various hierarchical and hollow nanostructures that assembled from nano-building blocks such as 0$D$ nanoparticles, 1-D nanowires, and 2-D nanosheets.

In contrast, high gas response and rapid responding speed can be accomplished simultaneously using hierarchical and hollow nanostructures, which are attributed to the fast and effective diffusion of analyte gas onto the entire sensing surfaces through well-defined porous structures. (Fig. 2b) 

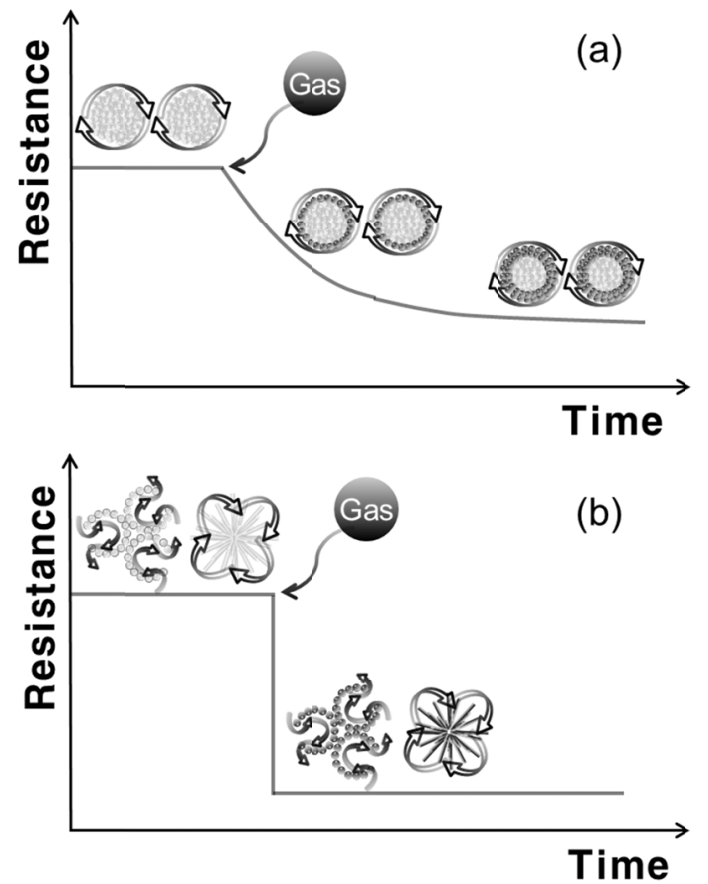

Fig. 2 Schematic sensing transients of (a) agglomerated oxide nanostructures (n-type semiconductor) and (b) hierarchical nanostructures (n-type semiconductor) to reducing gas.

\section{Surface modification of oxide nanostructures}

Gas response and selectivity of hierarchical and hollow nanostructures can be enhanced or tuned using the noble metal catalysts or metal oxide additives. The roles of noble metal or metal oxide catalysts on the gas sensing characteristics are the catalytic promotion of surface reaction, the electronic interaction between additive and sensing materials, and the control of acid-base properties. To date, various noble metal catalysts such as $\mathrm{Pd}, \mathrm{Pt}, \mathrm{Au}$, and $\mathrm{Ag}$ have been explored to enhance the gas sensing characteristics of oxide semicondutor gas sensors.

The effect of $\mathrm{Rh}$ loading on the gas sensing characteristics of $\operatorname{In}_{2} \mathrm{O}_{3}$ hollow structures was investigated. Pure and Rhloaded $\ln _{2} \mathrm{O}_{3} \quad\left(\ln _{2} \mathrm{O}_{3}\right.$ and $\left.\mathrm{Rh}-\mathrm{In}_{2} \mathrm{O}_{3}\right)$ hollow spheres with the diameters of $\sim 2 \mu \mathrm{m}$ were prepared by hydrothermal reaction of aqueous solution containing indium nitrate, rhodium chloride, and glucose and subsequent heat treatment [2]. The Rh concentration in Rh- $\ln _{2} \mathrm{O}_{3}$ hollow spheres was determined to be 1.67 at $\%$ by inductively coupled plasma mass spectroscopy.

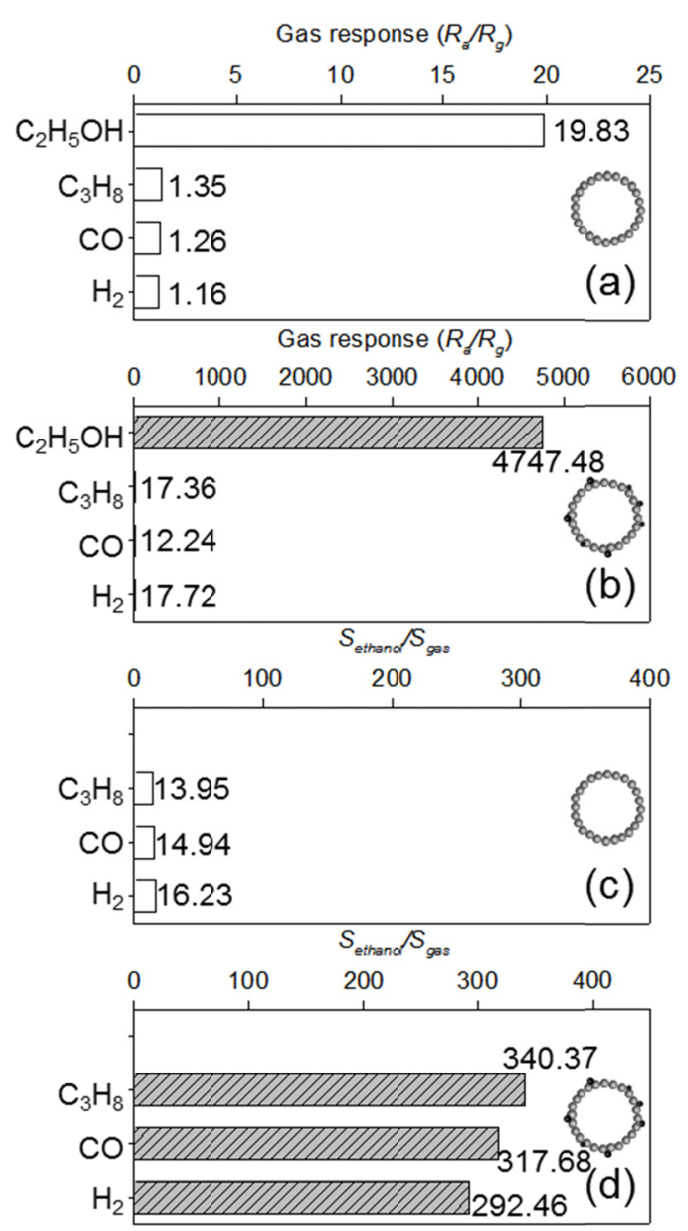

Fig. 3 Gas responses $\left(R_{a} / R_{i g}, R_{a}\right.$ : resistance in air, $R_{g}$ : resistance in gas) to $100 \mathrm{ppm} \mathrm{C}_{2} \mathrm{H}_{5} \mathrm{OH}, \mathrm{C}_{3} \mathrm{H}_{8}, \mathrm{CO}$, and $\mathrm{H}_{2}$ and selectivity to ethanol $\left(\mathrm{S}_{\text {ethanol }} / \mathrm{S}_{\text {gas }}, \mathrm{S}_{\text {ethanol: }}\right.$ gas response to $100 \mathrm{ppm} \mathrm{C}_{2} \mathrm{H}_{5} \mathrm{OH}, \mathrm{S}_{\text {gas: }}$ : gas response to $100 \mathrm{ppm}$ interference gas) at $371^{\circ} \mathrm{C}$ : (a) gas response of $\mathrm{In}_{2} \mathrm{O}_{3}$ hollow spheres; (b) gas response of $\mathrm{Rh}$ - $/ \mathrm{I}_{2} \mathrm{O}_{3}$ hollow spheres; (c) selectivity to ethanol of $\mathrm{In}_{2} \mathrm{O}_{3}$ hollow spheres; (d) selectivity to ethanol of $\mathrm{Rh}-\mathrm{In}_{2} \mathrm{O}_{3}$ hollow spheres

The gas response $\left(R_{a} / R_{g}, R_{a}\right.$ : resistance in air, $R_{g}$ : resistance in gas) of $\ln _{2} \mathrm{O}_{3}$ hollow spheres to $100 \mathrm{ppm} \mathrm{C}_{2} \mathrm{H}_{5} \mathrm{OH}$ was 19.83 at the sensor temperature of $371{ }^{\circ} \mathrm{C}$, which was substantially higher than those to $100 \mathrm{ppm} \mathrm{C}_{3} \mathrm{H}_{8}$, $\mathrm{CO}$, and $\mathrm{H}_{2}$ (Fig. 3a). The loading of $1.67 \mathrm{at} \%$ of $\mathrm{Rh}$ markedly increased the response to 100 ppm $\mathrm{C}_{2} \mathrm{H}_{5} \mathrm{OH}$ up to 4747.48 , while the enhancement in the responses to $\mathrm{C}_{3} \mathrm{H}_{8}, \mathrm{CO}$, and $\mathrm{H}_{2}$ were not very high (Fig. $3 b$ ). The selectivity to ethanol $\left(S_{\text {ethano }} / S_{\text {gas }}, S_{\text {ethanol: }}\right.$ response to $100 \mathrm{ppm} \mathrm{C}_{2} \mathrm{H}_{5} \mathrm{OH}, S_{\text {gas }}$ : response to $100 \mathrm{ppm}$ interference gas) was calucluated. The $S_{\text {ethano }} / S_{\text {gas }}$ values of $\mathrm{Rh}-\mathrm{In}_{2} \mathrm{O}_{3}$ hollow spheres ranged from 292.46 to 340.37 , while those of $\ln _{2} \mathrm{O}_{3}$ hollow spheres were in the range between 13.95 and 16.23 (Fig. 3c,d). This clearly indicates that the selectivity to ethanol as well as ethanol response can be enhanced to a significant degree by loading Rh. 


\section{Nano scale oxide $p-n$ junctions}

The $\mathrm{p}-\mathrm{n}$ junctions in $\mathrm{Si}$ and compound semiconductors have been widely used to fabricate various applications such as transistors, solar cells and light emitting diodes. The regions near the $p-n$ junctions are quite different to those far from the junction in the viewpoint of charge carrier concentration and the potential barrier. This can be used to design oxide semiconductor gas sensors.

There have been many researches on the n-type oxide semiconductor gas sensors such as $\mathrm{SnO}_{2}, \operatorname{In}_{2} \mathrm{O}_{3}, \mathrm{ZnO}, \mathrm{TiO}_{2}$, and $\mathrm{WO}_{3}$. The representative p-type oxide semiconductors for gas sensor applications are $\mathrm{CuO}, \mathrm{NiO}, \mathrm{Cr}_{2} \mathrm{O}_{3}$, and $\mathrm{Co}_{3} \mathrm{O}_{4}$. The electron depletion layer and hole depletion layer will be formed near the junction of the n- and p-type semiconductors, respectivley. The donor density is one of key parameters to determine the gas response in oxide semiconductor sensors. The charge carrier depletion near the junction can also change the gas responses of n-type and p-type oxide semiconductor sensors. In addition, most of p-type semiconductors can play the roles of catalysts to promote gas sensing reactions. Thus, the formation of oxide $p-n$ junction can be used to enhance the gas selectivity and gas response.

The n-type $\mathrm{ZnO}$ nanowires (thickness: 30 $70 \mathrm{~nm}$ ) decorated with the discrete configuratoins of p-type $\mathrm{CO}_{3} \mathrm{O}_{4}$ nano-islands have been prepared by the vapor phase route and their gas sensing characteristics were investigated [3]. Pristine $\mathrm{ZnO}$ nanowires were also prepared for comparison. Both of $\mathrm{ZnO}$ and $\mathrm{Co}_{3} \mathrm{O}_{4}$-decorated $\mathrm{ZnO}$ nanowires showd the $\mathrm{n}$ type gas sensing behaviors, that is, the resistance increase by oxidizing gas and resistance decrease by reducing gases. This means that the conduction across the $\mathrm{Co}_{3} \mathrm{O}_{4}$ decorated $\mathrm{ZnO}$ nanowires is governed not by $\mathrm{p}$ type $\mathrm{CO}_{3} \mathrm{O}_{4}$ nanoclusters with discrete configuration but by n-type $\mathrm{ZnO} \mathrm{NWs}$ with connecting configuration. Thus, the $R_{g} / R_{a}$ and $R_{a} / R_{g}$ values were used for gas responses to $\mathrm{NO}_{2}$ and $\mathrm{C}_{2} \mathrm{H}_{5} \mathrm{OH}$, respectively. At the sensor temperature of $200{ }^{\circ} \mathrm{C}$, the response $\left(R_{g} / R_{a}\right)$ to 5 ppm $\mathrm{NO}_{2}$ was as high as 46.48 while cross responses $\left(R_{a} / R_{g}\right)$ to $100 \mathrm{ppm} \mathrm{C}_{2} \mathrm{H}_{5} \mathrm{OH}, \mathrm{CO}, \mathrm{H}_{2}$, and $\mathrm{C}_{3} \mathrm{H}_{8}$ were negligible (Table 1a). This indicates that $\mathrm{NO}_{2}$ can be measured in a selective manner using pristine $\mathrm{ZnO}$ nanowires. However, at $400{ }^{\circ} \mathrm{C}$, the responses to $5 \mathrm{ppm}$ $\mathrm{NO}_{2}$ and 100 ppm $\mathrm{C}_{2} \mathrm{H}_{5} \mathrm{OH}$ become similar, which make the discrimination between $\mathrm{NO}_{2}$ and $\mathrm{C}_{2} \mathrm{H}_{5} \mathrm{OH}$ difficult. In contrast, $\mathrm{Co}_{3} \mathrm{O}_{4}$ decorated $\mathrm{ZnO}$ nanowires showed the selective detection of $\mathrm{NO}_{2}$ at $200{ }^{\circ} \mathrm{C}$ and selective detection of $\mathrm{C}_{2} \mathrm{H}_{5} \mathrm{OH}$ at $400{ }^{\circ} \mathrm{C}$. The deposition of discrete p-type $\mathrm{Co}_{3} \mathrm{O}_{4}$ nanoislands on n-type $\mathrm{ZnO}$ nanowires will enlarge the electron depletion layer in a radial direction of $\mathrm{ZnO}$ nanowires, which will increase sensor resistance. This is supported by the fact that the resistances in air $\left(R_{a}\right)$ of $\mathrm{Co}_{3} \mathrm{O}_{4}$-decorated $\mathrm{ZnO}$ nanowires sensors were $8-60.1$ times higher than those of $\mathrm{ZnO}$ nanowires sensors at 200 $400{ }^{\circ} \mathrm{C}$. The increase of $R_{a}$ will decrease the response to $\mathrm{NO}_{2}\left(R_{g} / R_{a}\right)$ and increase the response to $\mathrm{C}_{2} \mathrm{H}_{5} \mathrm{OH}\left(R_{a} / R_{g}\right)$. This says that the formation of oxide $p-n$ junciton can be used to tune the responses to reducing and oxidizing gases. In addition, the catalytic effect of $\mathrm{CO}_{3} \mathrm{O}_{4}$ nano-island to promote the gas sensing reaction toward $\mathrm{C}_{2} \mathrm{H}_{5} \mathrm{OH}$ should be also taken into account.

Table 1: Gas responses of (a) prisinte $\mathrm{ZnO}$ nanowires and (b) $\mathrm{Co}_{3} \mathrm{O}_{4}$-decorated $\mathrm{ZnO}$ nanowires to $100 \mathrm{ppm} \mathrm{C}_{2} \mathrm{H}_{5} \mathrm{OH}$ and $5 \mathrm{ppm} \quad \mathrm{NO}_{2}$; (c) the resistances in air of two sensors

(a) $\mathrm{ZnO}$ nanowires

\begin{tabular}{|c|c|c|}
\hline $\mathrm{T}\left({ }^{\circ} \mathrm{C}\right)$ & $\begin{array}{c}\text { response to } \\
5 \mathrm{ppm} \mathrm{NO}_{2} \\
\left(R_{g} / R_{a}\right)\end{array}$ & $\begin{array}{c}\text { response to } \\
100 \mathrm{ppm} \mathrm{C}_{2} \mathrm{H}_{5} \mathrm{OH} \\
\left(R_{a} / R_{g}\right)\end{array}$ \\
\hline 200 & 46.48 & 1.0 \\
\hline 400 & 3.45 & 4.28 \\
\hline
\end{tabular}

(b) $\mathrm{Co}_{3} \mathrm{O}_{4}$-decorated $\mathrm{ZnO}$ nanowires

\begin{tabular}{|c|c|c|}
\hline $\mathrm{T}\left({ }^{\circ} \mathrm{C}\right)$ & $\begin{array}{c}\text { response to } \\
5 \mathrm{ppm} \mathrm{NO} \mathrm{NO}_{2} \\
\left(R_{g} / R_{a}\right)\end{array}$ & $\begin{array}{c}\text { response to } \\
100 \mathrm{ppm} \mathrm{C}_{2} \mathrm{H}_{5} \mathrm{OH} \\
\left(R_{a} / R_{g}\right)\end{array}$ \\
\hline 200 & 14.32 & 1.0 \\
\hline 400 & 1.36 & 21.94 \\
\hline
\end{tabular}

(c) the resistance in air $\left(R_{a}\right)$ of two sensors

\begin{tabular}{|c|c|c|}
\hline $\mathrm{T}\left({ }^{\circ} \mathrm{C}\right)$ & $R_{a}(\mathrm{ZnO})(\mathrm{M} \Omega)$ & $R_{a}\left(\mathrm{Co}_{3} \mathrm{O}_{4}-\mathrm{ZnO}\right)(\mathrm{M} \Omega)$ \\
\hline 200 & 0.75 & 6.00 \\
\hline 400 & 0.31 & 18.8 \\
\hline
\end{tabular}

\section{Humidity dependence of gas sensors}

The resistances, gas responses, responding and recovering speeds of oxide semiconductor gas sensors are known to depend significantly on the humidity because not only the analyte gas but also water vapor interact with oxide semiconductor surfaces. The loading of $\mathrm{NiO}$ on hierarchical $\mathrm{SnO}_{2}$ nanostructures is promising approach to reduce the humidity dependence of gas sensing characteristics to a negligible level [4]. 
$\mathrm{SnO}_{2}$ hierarchical structures assembled from nanosheets were prepared hydrothermal reaction and then $1.27 \mathrm{wt} \%$ of $\mathrm{NiO}$ was loaded. In dry atmospheres, the undoped $\mathrm{SnO}_{2}$ hierarchical structures showed high and rapid response to $50 \mathrm{ppm} \mathrm{CO}$ (dotted line, Fig. 4a). Under the atmosphere of $\mathrm{RH} 25 \%$, most of gas sensing characteristics such as gas response, responding speed and resistance in air were significantly deteriorated or changed (solid line, Fig. 4a). The loading of $1.27 \quad w t \% \quad \mathrm{NiO}$ enhanced the recovery speed in dry atmosphere (dotted line in Fig. 4b). And the $\mathrm{NiO}-$ loaded $\mathrm{SnO}_{2}$ sensor showed the negligible dependence of gas senisng characteristics on humidity (solid line in Fig. 4b). According to diffuse reflectance infrared transform measurement, it is found that the electrochemical interaction between humidity and $\mathrm{SnO}_{2}$ sensor surface is very small because most of water-related species are abosorbed not on $\mathrm{SnO}_{2}$ but on discrete configuration of $\mathrm{NiO}$.

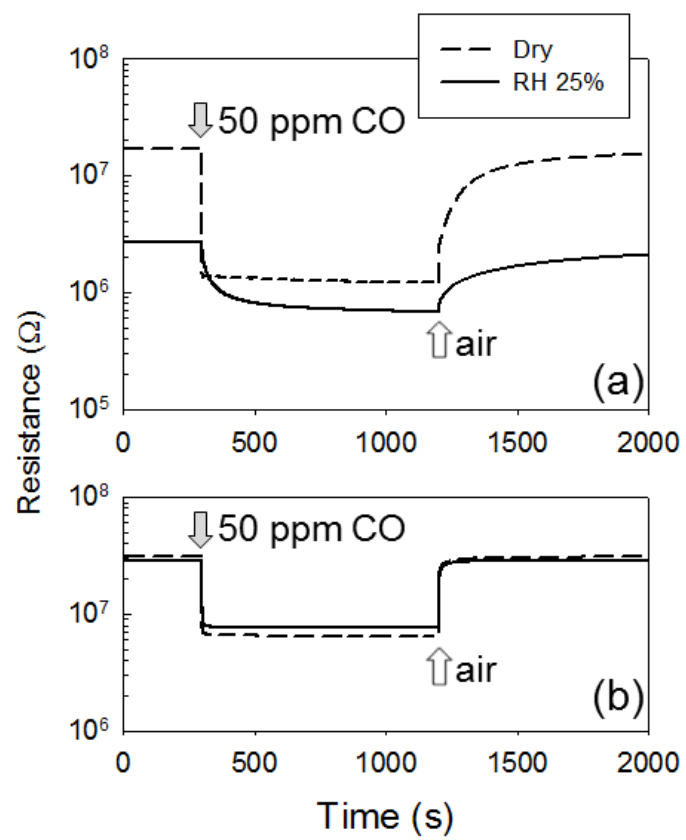

Fig. 4 Sensing transients of (a) $\mathrm{SnO}_{2}$ hierarchical nanostructures and (b) $1.27 \mathrm{wt} \% \mathrm{NiO}-$ loaded $\mathrm{SnO}_{2}$ hierarchical nanostructures to $50 \mathrm{ppm} \mathrm{CO}$ at $400{ }^{\circ} \mathrm{C}$ under dry and humid (RH 25\%) atmospheres.

\section{References}

[1] J. -H. Lee, Sens. Actuators B 140, 319-336 (2009)

[2] S. -J. Kim, I. -S. Hwang, C. -W. Na, I. -D. Kim, Y. C. Kang, J. -H. Lee, J. Mater. Chem. 21, 18744-18748 (2011)

[3] C. W. Na, H. -S. Woo, I. -D. Kim, J. -H. Lee, Chem. Commun. 47, 5148-5150, (2011)
[4] H. -R. Kim, A. Haensch, I. -D. Kim, N. Barsan, U. Weimar, J. -H. Lee, Adv. Funct. Mater. 21, 44564463 (2011) 